\title{
An Emotional Analysis of the Concept of Tahara I Function II
}

\author{
Daiki Horiuchi, Taiga Imanishi, Kento Nishi
}

ABSTRACT: It seems to be interesting however too difficult for almost people to understand.

KEYWORDS: Tahara I function, Tahara's Definition,

Date of Submission: 09-26-2019

\section{Analysis}

According to Tahara's definition (Tahara, 2019), Quran is correct if and only if Tahara $I$ function exists uniquely. Tahara $I$ function is defined as

$$
I=\sum i\left(i: 2^{[\mathrm{Q} . \mathrm{S} .]} \times 2^{[\text {T.P. }]} \longrightarrow 2^{[\text {T.P. }]} \wedge i: \text { meaningful }\right)
$$

however almost people who have never learned mathematics at a higher education institution perhaps cannot understand the meaning (Tinto, 1975). Therefore, emotionally speaking, the concept of Tahara $I$ function seems to be interesting however too defficult for almost people to understand.

\section{REFERENCES}

[1]. TAHARA, Hiroki. The Mathematical Expressions of Quranic Exegeses and the Mathematical Definition of the Quranic Correctness. OSF Preprints, 6dsxb, 2019.

[2]. TAHARA, Hiroki. Methodology to Prove the Quranic Correctness. OSF Preprints, 49qse, 2019.

[3]. TAHARA, Hiroki. A Brainstorming of the Quranic Studies Inspired by the Evaluation of Coefficients of Polynomials. OSF Preprints, 6n9p3, 2019

[4]. TINTO, Vincent. Dropout from Higher Education: A Theoretical Synthesis of Recent Research. Review of Educational Research, 1975, 45.1: 89-125. 